\title{
Demographic Factors As Determinant Of Effective Communication among Academic Library Personnel in South West, Nigeria
}

\author{
${ }^{1}$ Saheed Abiola Hamzat, ${ }^{2}$ Olalekan Abraham Adekunjo \\ ${ }^{I}$ Mba Library, University Of Ibadan P.O.Box 20199, U.I.Post Office, Ibadan,Nigeria \\ ${ }^{2}$ Kenneth Dike Library, University Of Ibadan
}

\begin{abstract}
The study focuses on demographic factors (education. Socio-economic and cultural background) as determinant of communication effectiveness among academic library personnel. Survey research method was adopted for this study whereby questionnaire was used to elicit response from respondents and samples were drawn from the personnel of libraries such as Kenneth Dike (UI), Lead City University Library, Nimbe Adedipe Library (FUNNAB) and Centre for Learning Resources (Covenant University).The total of 201 copies of questionnaire were found usable out of 209 distributed in the highlighted libraries. Purposive sampling technique was used based on the existing knowledge of the population. The study revealed that the level of education, as well as the cultural belief of library personnel plays a significant role in their information sharing pattern. The study also found out that low economic status affect effective communication among library personnel which in turn have impact on the services render to library clients. The study however concluded that effective communication is needed to modify behaviour, achieve productivity and meet goals.
\end{abstract}

Keywords: effective communication, demographic factors, academic libraries, library personnel

\section{Introduction}

Through the use of language, mankind has been able to record past history and transmit culture from one generation to the other. This transmission exercise lies on communication process without which managerial, administrative and academic functions will not be possible. According to Nakpodia (2010) communication system is very vital to the survival and smooth running of the organization and has assisted man to build himself, societies and other social groupings, which contribute to his survival and to give him more enjoyable patterns of living.

Biagi (2003) defines communication as the act of sending ideas and attitudes from one person to another. Communication is a transactional as well as an interactive process. It involves the sharing of opinions, thought and concepts. As a process, communication is an on going event, a continuous and ever changing activity (Beebe et.al, 1996).To some extent, animals and even plants do also communicate in one form or the other, but man as a social animal has developed sophisticated communication methods with which he communicates with other people in the same social environment in order for effective interaction and development to take place.

Communication exists within various contexts such as intra-personal communication, which involves only one person, as he acts, he interprets his behaviour. It could be inter-personal communication which involves the exchange of messages, sharing of opinions and ideas between at least two people. Another form of communication is the group communication which involves "one" to "many". Also there is organizational communication which takes place in an organization. As well as the mass -communication which is the type of communication that involves the transmission of messages through mass media channels.

Effective communication has been described as any initiated behaviour on the part of the sender which conveys the desired meaning to the receiver and causes desired response behaviour from the receiver. Effective communication is important to all phases of management by every individual within the system and is particularly important in directing and leading any system. Effective Communication is used to modify behaviour, achieve productivity and meet goals. It is the chief means through which an organization or its members influence or react to one another. It appears that the success of any library depends not only on having qualified personnel but also on the interaction among them (Koontz \& O'Donnell 2005). In fact without effective communication, organizations will not be what it is, and its functions will not be carried out effectively towards goal achievement.

In essence, library functions as communication agency for the purpose of attaining societal development. It can be regarded as a repository of knowledge which contains information of the past, present and future for the use of generality of all members of the society (Hoffman, 2005).One primary objective of any 
library is to maximize the intensive use of its resources and services. Therefore, the effectiveness of a library as an instrument of learning is determined by the success with which it is able to provide the user with relevant information. Library forms an integral component of a nation's national information system which is established for the purpose of meeting the nation's information needs in the academia, governance and in the industry (Zeleza, 2003).

Since libraries serve as communication agency, it is imperative to examine some factors that determine the effectiveness of communication in library setting. The knowledge and application of demographic factors (age, gender, educational background, culture and income) are important to the effectiveness of communication of library personnel which will in turn bring efficient library and information service delivery. In order to be able to perform organization should critically look at cultural background, level of education as well as other socio-economic factors of personnel and know how best they can satisfy them

In other word, culture can be regarded as the accumulative deposit of knowledge, experience, meanings, beliefs, values, attitudes, religions, concepts of self, the universe, and self-universe relationships, hierarchies of status, role expectations, spatial relations, and time concepts acquired by large group of people in the course of generations through individual's arid group are all referred to as culture (Markel, 2009). Culture is a complex of values, ideas, attitude and other meaningful symbols created by people to shape human behaviour and the artefacts of that behaviour as they are transmitted from one generation to the other. Understanding more about culture can be a real bonus when working as part of any organization.

Culture can be used to embrace peoples' art, music, literature, philosophy, religion as well as other ideas and values, implicit and explicit that permeates a society and binds its people into a recognizable unit. Osokoya (2003) concurs that education can be used to assist members of societies to understand the heritage of the past and to participate productively in the future. Education may be formal, informal and non formal. Formal education is the kind of education that is systematically organized and sequentially structured. It is informal when there is no syllabus, scheme of work or preparation of lesson notes and this involves the influences of elders, parents and siblings on the life of individuals outside the classroom. Non formal type of education is geared towards achieving specific objectives. However, unlike formal system of education the activities of nonformal education are not limited to a period of time.

Huttenlocher and Dabholkar (1997) in their own submission observed that personnel with higher educational level seem to perform effectively in any given tasks than personnel with lower educational level. There are several explanations for education-related inequalities within and between countries which include poverty and ignorance especially in most developing countries. The effect of education varies from one person to another which makes them behave differently in an organization.

Socio-economic factors such as personal income (GDP per capita), inflation, income inequality etc. appear to be an important indicator in employee effectiveness in an organization Splettstoesser and TowryCoker,1999). It appears that the higher the incomes and the level of education the higher the effectiveness of personnel. To this end, without adequate communication, people cannot live peacefully in any society since the effectiveness of communication defines the level of interaction among people. In any communication system feedback has been identified as essential tool in evaluating understanding.

\section{Statement of the Problem}

The need for effective communication in organization, especially in libraries cannot be ignored due to the fact libraries are made up of human beings, who must, as a matter of necessity, interact toward the achievement of the organizational goals. Moreover, there are variations in level of education, age, income as well as cultural background of personnel in any given organization which determine how effective and harmoniously they interact as a team. However, it is uncertain whether improvement in culture, or socioeconomic variables may increase the performance of library staff since no one can manage a modern organization without competence in communication principles and technique.

In a nutshell, when communication among the library staff is not effective it may hamper efficient library service since the effectiveness of a library as a social institution is determined by the success with which it is able to provide the user with relevant information. Overtime conscious effort has been taken to study the crucial role human resources play in library management. However, little or no attempt has been taken to study various factors that could facilitate effective communication among employee of a library. Hence there is need to investigate demographic factors as determinants of effective communication among academic library personnel in South West, Nigeria.

\section{Objectives of the Study}

The objectives of this study are set out to:

- Find out the influence of culture on effective communication among academic library staff; 
- Examine the various educational factors influencing effective communication among academic library staff;and

- Investigate socio-economic factors influencing effective communication among academic library staff

\section{Concept and Organisational Communication}

\section{Literature Review}

Communication is the heart of our everyday life from the moment we wake in the morning to the moment we drift off to sleep at night; we are constantly in the process of communication. It is also a basic fact that human beings live in social groups, and the people in these social groups interact with one another in order to understand their environment, develop new ideas, solve problems and to have better understanding of one another which will eventually lead to an improvement in their lifestyles. Thus, human beings often exchange ideas and information that could be of benefit to their well being.

The communication processes within an organization can be examined in the context of how organizations function. Organizations exist to perform specific functions and this demand restricting organizational communications to facilitating the effective performance of those functions. As katz and Khan (1978) pointed out, "to move from an unorganised state to an organised state requires the introduction of constraints and restrictions to reduce diffuse and random communication channels appropriate for the accomplishment of organisational goals.

Thus, the very nature of organised systems implies selectivity of channels and the communicative act. The technique employed by organizations to impose such constraints and restrictions and to establish communication channels that are appropriate for attaining organizational goals. The functional interconnectedness inherent in the organization structure facilitates the flow of communication within and among the parts. Thus, management scholars have come to conceive of formal organizational communication as having three dimensions: downward, upward, horizontal or lateral.

\section{Communication Effectiveness in Academic Libraries}

Communication is the transfer of information from a source to a receiver. It is effective when the sender of information and the recipient have a common comprehension of the message. The importance of communication in the world in which we live today cannot be overstressed. Academic libraries are information centres established in tertiary institutions. It transmits information needed by staff, students, and researchers in the university community.

Communication is the chief means through which an organization or its members influence or react to one another. The success of any library depends not only on having qualified personnel but also on the interaction among them. Lesikar (1999) says that "communication is the ingredient which makes organization possible". To achieve its objectives, libraries must have effective communication systems. Emojorho (2010) citing Merrihue (1980) defines effectiveness of communication "as any initiated behaviour on the part of the sender which conveys the desired meaning to the receiver and causes desired response behaviour from the receiver".

Communication effectiveness in library setting involves two or more people (a sender and receiver). Anene (2006) opines that the success of any organization depends not only upon provision of qualified personnel and efficiency of its staff, but also on the interaction between the personnel and clientele. Therefore, communication is very significant to the life of any administration because it is a major means through which they give orders, directions, requests, report, receive rumours and other information.

Hoy and Miskel (1998) identify three criteria of communication effectiveness. The first is the qualities and presentation of message: clarity, timing, consistency, and mutual interest. Second is the achievement of desired results. Third is the time perspective. Thayer (1991) also lists primary functions of administrative communication: informing, instructing or directing, evaluating and influencing. In the university library, the university librarian must take care to identify the audience. The sender must use language that corresponds to the receiver's status. To achieve effective communication, the communicator must encode the message to fit the relationship between the sender and the receiver to reduce distortion.

\section{Influence of Education on Effective Communication in Academic Libraries}

Every profession in this modern age must continuously adapt itself to the rapidly evolving technological society. Keeping up with the today's constant change and innovation is a challenging task, but one must undertake it to operate successfully in the world. The task is formidable because new information is appearing at an overwhelming rate. The proliferation of knowledge, referred to earlier as the "information explosion" and recently as the "information revolution," is affecting all professionals; but none more than the librarian. As they are located at the center of the blast, they must hasten to implement the advancements in library science in order to handle the mass of new information in all the areas of knowledge (Chaudhary,2001). 
Academic libraries have special characteristics and functions of their own, which give the academic librarian a special responsibility for professional growth. The basic purpose of an academic library is to support academic programmes of the parent institution. In other words, the primary characteristic of a good academic library is its complete identification with its own institution. The measure of its excellence is the extent to which its resources and services support the institution's objectives. The academic library should and does promote the necessary means to support the institution's objectives. These methods require that academic librarians must be willing to go beyond acquiring and making available the usual library materials in establishing innovative library services, such services that may vary from one library to another and from one librarian to another for the basic purpose of translating the institution's objectives into meaningful services.

According to Chaudhary (2001) citing Gates (1968) continuing education is essential for all library personnel, professional as well as supportive, whether they remain within a position category or are preparing to move into a higher one. Continuing education opportunities include both formal and informal learning situations, and need not be limited to library subjects or the offerings of library schools. Continuing education can be had through both formal and informal means and it enables a professional to perform his/her role effectively and efficiently. The continuing professional education of librarians is a vital issue throughout the library world; because immense technological developments are causing rapid shifts and changes in the library profession.

\section{Methodology}

Purposive sampling technique was used based on the existing knowledge of the population. The respondents were selected based on certain considerations such as education, ethnicity, and other socioeconomic characteristics. The sampling was based on the researcher's expert knowledge of the study areas. The population of this study comprised all categories of library personnel (professional, para-professional and support staff) in selected academic libraries; that is Kenneth Dike Library, (University of Ibadan), Centre for Learning Resources (Covenant University),Lead City University Library and Nimbe Adedipe Library (Federal University of Agriculture Abeokuta). As at the time of commencement of this study there were seventy six (76) professional staff, one hundred and ten (110) para-professional staff and fifty three(53) support staff totalling two hundred and thirty nine(239) personnel in the four selected academic libraries. Two hundred and one (201) copies of questionnaire were retrieved and found usable out of two hundred and eight (208) returned. The data collected through questionnaire were appropriately coded with the use of SPSS data analysis software.

Table 1:

Socio-Demographic Characteristics of Respondents

\begin{tabular}{|l|l|l|}
\hline Institutions/Libraries & Frequency & Percentage \\
\hline Kenneth Dike (U.I) & 26 & 13.3 \\
CLR (Covenant University) & 56 & 28.7 \\
Nimbe Adedipe (FUNNAB) & 79 & 40.5 \\
Lead City Library & 35 & \\
Total & 195 & \\
Missing System & 6 & 17.4 \\
Total & 201 & 100.0 \\
\hline Educational Qualification & Frequency & Percentage \\
\hline WAEC/SSCE or Equivalent & 39 & 20.0 \\
ND & 32 & 16.4 \\
HND & & 15.9 \\
First Degree & 31 & 17.9 \\
Masters & 35 & 26.7 \\
Ph.D & 52 & 3.1 \\
Total & 6 & 100.0 \\
Missing system & 195 & \\
Total & 6 & \\
& 201 & \\
\hline
\end{tabular}

Source: Field survey 2012

The table shows the distribution of respondents in the study areas. The table shows that $13.3 \%$ of the respondents are from Kenneth Dike Library, $28.7 \%$ of the respondents are from Covenant University library, $40.5 \%$ of the respondents are from Nimbe Adedipe Library and $17.4 \%$ of the respondents are from Lead City University Library. It is evident from table that most of the respondents had a masters degree as their highest educational qualification which constitute $26.7 \%$ of the respondents. 
Table 2:

Research Question 1: What is the impact of Culture on Effective Communication among Library Personnel?

\begin{tabular}{|c|c|c|}
\hline My cultural believe affect my information sharing pattern & Frequency & Percentage \\
\hline Strongly Agree & 36 & 18.1 \\
\hline Agree & 88 & 44.2 \\
\hline Disagree & 60 & 30.2 \\
\hline Strongly Disagree & 15 & 7.5 \\
\hline Total & 199 & 100.0 \\
\hline Missing System & 2 & \\
\hline Total & 201 & \\
\hline I am proud of my ethnic/cultural background and belief & Frequency & Percentage \\
\hline Strongly Agree & 75 & 37.7 \\
\hline Agree & 78 & 39.2 \\
\hline Disagree & 32 & 15.9 \\
\hline Strongly Disagree & 14 & 7.0 \\
\hline Total & 109 & 99.0 \\
\hline Missing System & 2 & 1.0 \\
\hline Total & 201 & 100.0 \\
\hline $\begin{array}{l}\text { My Cultural background make me feel superior to my } \\
\text { colleagues from other ethnic group }\end{array}$ & Frequency & Percentage \\
\hline Strongly Agree & 39 & 19.6 \\
\hline Agree & 87 & 43.7 \\
\hline Disagree & 48 & 24.1 \\
\hline Strongly Disagree & 25 & 12.6 \\
\hline Total & 199 & 100.0 \\
\hline Missing system & 2 & \\
\hline Total & 201 & \\
\hline $\begin{array}{l}\text { I bear my colleagues cultural characteristics in mind while } \\
\text { communicating }\end{array}$ & Frequency & Percentage \\
\hline Strongly Agree & 53 & 26.9 \\
\hline Agree & 79 & 40.1 \\
\hline Disagree & 52 & 26.4 \\
\hline Strongly Disagree & 13 & 6.6 \\
\hline Total & 197 & 100.0 \\
\hline Missing System & 4 & \\
\hline Total & 201 & \\
\hline $\begin{array}{l}\text { I do not believe culture has anything to do with } \\
\text { communication }\end{array}$ & Frequency & Percentage \\
\hline Strongly Agree & 38 & 19.3 \\
\hline Agree & 87 & 44.2 \\
\hline Disagree & 58 & 29.4 \\
\hline Strongly Disagree & 14 & 7.1 \\
\hline Total & 197 & 100.0 \\
\hline Missing System & 4 & \\
\hline Total & 201 & \\
\hline
\end{tabular}

Source: Field survey 2012

Table 2 indicates that $76.9 \%$ of the respondents are proud of their ethnic/cultural background and beliefs. It further revealed that $63.5 \%$ of the respondents believed that culture has anything to do with communication. The table also shows that $67 \%$ of the respondents bear their colleagues' cultural characteristics in mind while communicating with them". It shows that $62.3 \%$ of the respondents agreed that their cultural belief affected the way they share information with their colleagues. 
Table 3:

Research Question 2: What is the Influence of education on effective communication among library personnel?

\begin{tabular}{|l|l|l|}
\hline Higher level of education enhances effective & Frequency & Percentage \\
communication & & \\
\hline Strongly agree & 61 & 30.7 \\
Agree & 92 & 46.2 \\
Disagree & 36 & 18.1 \\
Strongly Disagree & 10 & 5.0 \\
Total & 199 & 100.0 \\
Missing System & 2 & \\
Total & 201 & \\
\hline My level of education, training and conferences enhance my & Frequency & Percentage \\
communication skill & & \\
\hline Strongly Agree & 59 & 29.6 \\
Agree & 81 & 40.7 \\
Disagree & 41 & 20.6 \\
Strongly Disagree & 18 & 9.0 \\
Total & 199 & 100.0 \\
Missing System & 2 & \\
Total & 201 & \\
\hline My level of education greatly influences my relationship \\
with library clients and colleagues & Frequency & Percentage \\
\hline Strongly Agree & 60 & \\
Agree & 90 & 30.3 \\
Disagree & 35 & 45.5 \\
Strongly Disagree & 13 & 17.7 \\
Total & 198 & 6.6 \\
Missing System & 3 & 100.0 \\
Total & 201 & \\
\hline I communicate only with my colleagues that possess same & Frequency & \\
level of education & & Percentage \\
\hline Strongly Agree & 26 & \\
Agree & 48 & 12.9 \\
Disagree & 84 & 23.9 \\
Strongly Disagree & 41 & 20.4 \\
Total Missing System & 199 & 109.0 \\
Total & 2 & \\
\hline Solat & 201 & \\
\hline & & \\
\hline
\end{tabular}

Source: Field survey 2012

The table shows various educational factors that influence effective communication among academic library staffs.76.9\% of the respondents agreed that higher level of education enhance effective communication, It also revealed that $70.4 \%$ feels that their level of education, training and conferences enhances their communication skills. It further shows that $75.8 \%$ agrees that their level of education also greatly influences their relationship with their colleagues and clients of the library and lastly the table shows that $62.8 \%$ of the respondents strongly disagreed that they communicate only with their colleagues that posses the same level of education.

Table 4:

Research Question 3: What is the influence of socio-economic factors on effective communication?

\begin{tabular}{|l|l|l|}
\hline Low Economic status affect effective communication & Frequency & Percentage \\
\hline Strongly Agree & 37 & 18.7 \\
Agree & 91 & 46.0 \\
Strongly Disagree & 15 & 27.8 \\
$\begin{array}{l}\text { Total } \\
\text { Missing System } \\
\text { Total }\end{array}$ & 198 & 7.6 \\
\hline $\begin{array}{l}\text { My socio-background influences the way I communicate } \\
\text { with colleagues in library }\end{array}$ & 201 & 100.0 \\
\hline Strongly Agree & Frequency & Percentage \\
\hline \multicolumn{2}{|c|}{ www.iosrjournals.org } & 18.1 \\
\hline
\end{tabular}




\begin{tabular}{|l|l|l|}
\hline Agree & 83 & 41.7 \\
Diasgree & 62 & 31.2 \\
Strongly Disagree & 18 & 9.0 \\
Total & 199 & 100.0 \\
Missing System & 2 & \\
Total & 201 & Percentage \\
\hline I render full responsibility without considering my level of & Frequency & \\
income & & 22.1 \\
\hline Strongly Agree & 44 & 46.7 \\
Agree & 93 & 19.1 \\
Disagree & 38 & 12.1 \\
Strongly Disagree & 24 & 100.0 \\
Total S & 199 & \\
Missing System & 2 & \\
Total & 201 & Percentage \\
\hline I feel shy to when communicate with my superior & Frequency & 30.8 \\
\hline Strongly Agree & 61 & 28.8 \\
Agree & 57 & 21.2 \\
Disagree & 42 & 19.2 \\
Strongly Disagree & 38 & 100.0 \\
Total & 198 & \\
Missing System & 3 & \\
Total & 201 & \\
\hline
\end{tabular}

Source: Field survey 2012

Table 4 shows that $64.6 \%$ of the respondents agree that low economic status affect effective communication. It further indicates that $59.8 \%$ of the respondents believe that their socio background influences the way they communicate with their colleagues in the library. In addition, the table shows that $68.8 \%$ of the respondents strongly agree that they render their full responsibility without considering their level of income. The table revealed that $59.6 \%$ of the respondents submit that they experience shyness when communicating with their superior colleagues at work

\section{Discussion of Findings}

The importance of effective communication cannot be underestimated in enhancing efficiency and effectiveness of library services. However, the analysis of duly completed questionnaire revealed that most of the library personnel are proud of their ethnic/cultural background which makes them bear their counterparts culture in mind while relating in the library organization. In a similar study conducted by Otitie (2010), he asserted that each ethnic group members share an exclusive culture and normative behaviour; an identity which they use as a means of forging relationship within political and economic spheres and in accessing resources.

In addition, the level of education of personnel has significant impact on his relationship with other library staff and clients of the library. This result is consistent with several previous empirical studies such as Huttenlocher and Dabholkar (1997) who observed that personnel with higher educational level seem to perform effectively in any given tasks than personnel with lower educational level.

Also, much has been said, on the socio-economic indicators in measuring personnel performance. For instance, Splettstoesser and Towry-Coker (1999) elucidated that Socio-economic factors such as personal income (GDP per capita), inflation, income inequality etc. appear to be an important indicator in employee effectiveness in an organization It appears that most of the respondents place emphasis on high income as a motivational factor to render their service optimally

In conclusion, from the review of various works and researches on communication in library, thus this paper adds to the existing literature by showing that communication effectiveness involves two or more people (sender and receiver) which must possess some attributes such as cultural belief, education and level of income just as established in the literature. Since every organization is out to perform specific functions, thus the findings of the study suggest that library management should place emphasis on demographic factors (such as education, socio-economic status and cultural background) that can facilitate effective communication which will in turn enhances effective service delivery.

\section{Summary and Conclusion}

The study concludes that the educational status of library personnel greatly influences their relationship with library clients as well as colleagues. The study shows the influence of socio-economic factors 
on effective communication among library personnel. It revealed that low economic status affect effective communication among library personnel which in turn have impact on their services to library clients.

The study shows the barriers to effective communication among library personnel. Inferiority complex has been identifies as significant factor which affect effective communication and also the intonation of library staff do not make them curtail information to themselves. It could be deduced from this study that effective communication is important to all phases of management by every individual within the system and is particularly important in directing and leading in library setting. Without mincing words, it is clear and evident that effective communication is used to modify behaviour, achieve productivity and meet goals

\section{Recommendations}

Guided by the findings of this study, the following recommendations were proffered:

- Adequate emphasis should be place on library personnel training through workshop, seminars, in-house training and overseas training on communication in work setting

- It is necessary for the academic library management to make a concerted effort in ensuring job satisfaction of the personnel through enhanced pay package etc

- In addition, a platform should be created whereby there will be a mutual relationship between the junior and senior staff in the library.

\section{References}

[1]. Nakpodia E.D 2010,The influence of communication on administration of secondary schools in Delta State, Nigeria International NGO Journal Vol. 5(8), pp. 194-198,

[2]. Biagi, S. (2003). Media impact: An introduction to mass media (6th ed.). Belmont CA: Wadsworth.

[3]. Koontz, H., \& O’Donnell, C. (2005). Management: A systems and contingency analysis of managerial functions. New York: McGraw-Hill Book Company.

[4]. Hoffman, Katty 2005.Professional Ethics and Librarianship: Texas Library Journal Fall 2005:7:11

[5]. Markel, Paulette 2009. Cultural Differences Impact Workplace Communication Retrieved from: http://www.alliancetac.com/?PAGE_ID=2560

[6]. Osokoya, I.O. 2003, Education in Nigeria: History, Strategies, Issues and problems.-Ibadan, Laurel Educational Publishers.

[7]. Huttenlocher, P. R. and Dabholkar, A. S. 1997. Regional differences in synaptogenesis in human cerebral cortex. Journal of Comparative Neurology, 387, 167-178.

[8]. Splettstoesser, D., and Towry-Coker, A. (1999). Model of an information and decision center for developing countries. JGIMT 2(1).

[9]. Katz D.and khan R.1978 (2ed) The Social Psychology or Organization;Wiley New York :ISBN:0471023558 vi,838p.

[10]. Lesikar, R.V., Pettit, J.D., \& Darsey, N.S. (1999). Communication in business. London: Longman

[11]. Emojorho Daniel 2010, The Role of Effective Communication in Enhancement of Library Services: An Overview of Delta State University Library, Abraka Library Philosophy and Practice 2010 (October)

[12]. Anene, M. (2006). Effectiveness of communication in administration. Abraka: Delta State University

[13]. Hoy, W.K., \& Miskel, C.G. (1998). Educational administration theory, research and practice. U.S.A.: Random House.

[14]. Thayer, L.O. (1991). Communication and communication systems. Homewood, Ill.: Irwin.

[15]. Chaudhary Muhammad Yaqub 2001. Continuing Professional Education of Librarians working in the University Libraries of Pakistan and Azad Jammu and Kashmir INSPEL vol.35 no.1, pp. 67-73

[16]. Dadzie, Perpetua S. 2005, Information Management, Accra: Institute of Adult Education, University of Ghana, 101p.

[17]. Otite, O (2010). Nigeria Identifiable Ethnic Group.Retrieved 18 October,2012, from http://www.onlinenigeria.com/tribes.asp 